\title{
Monika Kulesza, Le romanesque dans les Lettres de Madame de Sévigné
}

\section{Cecilia Russo}

\section{Q OpenEdition \\ 1 Journals}

\section{Edizione digitale}

URL: http://journals.openedition.org/studifrancesi/4355

DOI: 10.4000/studifrancesi.4355

ISSN: 2421-5856

\section{Editore}

Rosenberg \& Sellier

\section{Edizione cartacea}

Data di pubblicazione: 1 settembre 2016

Paginazione: 323

ISSN: 0039-2944

\section{Notizia bibliografica digitale}

Cecilia Russo, «Monika Kulesza, Le romanesque dans les Lettres de Madame de Sévigné ", Studi Francesi [Online], 179 (LX | II) | 2016, online dal 01 septembre 2016, consultato il 18 septembre 2020. URL : http://journals.openedition.org/studifrancesi/4355 ; DOI : https://doi.org/10.4000/studifrancesi.4355

Questo documento è stato generato automaticamente il 18 settembre 2020.

\section{(c) (i) $\odot$}

Studi Francesi è distribuita con Licenza Creative Commons Attribuzione - Non commerciale - Non opere derivate 4.0 Internazionale. 


\title{
Monika Kulesza, Le romanesque dans les Lettres de Madame de Sévigné
}

\author{
Cecilia Russo
}

\section{NOTIZIA}

MONIKA KULESZA, Le romanesque dans les Lettres de Madame de Sévigné, Frankfurt, Peter Lang, 2014, 178 pp.

1 Si tratta di uno studio che si prefigge di analizzare gli aspetti romanzeschi presenti nelle lettere della marchesa di Sévigné. L'A. chiarisce fin dal principio che, sebbene l'oggetto delle lettere possa essere considerato futile, costituito per lo più da commenti a eventi parigini che la marchesa voleva riportare alla figlia, Françoise de Grignan, che si trovava a Aix-en-Provence, lo stile e l'accuratezza del racconto permettono di definire questa corrispondenza una vera e propria opera letteraria, molto più che una semplice causerie.

2 La prima parte dello studio, intitolata «Le roman de la vie», si occupa di evidenziare quanto il "romanesque" influenzi sia la vita della marchesa sia la sua produzione letteraria.

3 La marchesa utilizza spesso un vocabolario attinente all'ambito letterario (afferma ella stessa: «j'écris romanesquement») e i protagonisti dei romanzi le servono da simbolo per evocare tutto un insieme di idee e di stati d'animo (è il caso del Don Quichotte). Quando un paesaggio o una persona le ricordano una situazione letteraria, Madame de Sévigné dà una descrizione romanzesca, come per esempio in una lettera del 24 luglio 1689 in cui parla del fascino di un giovane: «imaginez-vous un homme de taille toute parfaite, d'un visage romanesque, qui danse d'un air fort noble» (III, 649). Senza riferirsi ad un'opera precisa, la marchesa restituisce un'atmosfera o un paesaggio riconducibili al genere romanzesco.

4 Nelle Lettres il termine roman spesso significa histoire, non solo nel senso di relation o récit, ma anche con una connotazione di inverosimiglianza, di invenzione, in cui spesso 
la visione romanesque della realtà quotidiana non dipende dai fatti, ma dalla capacità della marchesa di scorgere in essa i tratti del romanzo.

Nella seconda parte dello studio, «Le roman dans les lettres», l'A. ribadisce lo stretto rapporto della marchesa con i romanzi, in particolare con il romanzo moderno che stava emergendo all'epoca in Francia, e sottolinea anche il grande amore di Madame de Sévigné per i "classici" come l'lliade, i romanzi di Cervantes e il poema storico, in particolare quello di Tasso. L'A. analizza le tematiche tipiche dei romanzi quali l'amore, la guerra e la morte, mettendo in risalto quanto questi argomenti pervadano tutta la produzione letteraria della marchesa.

Dal punto di vista della scrittura, Madame de Sévigné, lettrice colta e raffinata, riproduce lo stile romanzesco: in ogni lettera vi è una frase introduttiva attraverso la quale si prepara il lettore allo sviluppo del racconto, mettendolo in attesa e suscitando la sua curiosità. Le frasi sono brevi e l'utilizzo del presente avvicina la storia al lettore.

7 Nella terza e ultima parte dello studio, “"Telles un roman...”», si analizzano nel dettaglio la narrazione, la descrizione, i personaggi e i tempi delle lettere. L'A. concorda con il pensiero di alcuni critici che hanno definito lo stile che la marchesa utilizza per certi racconti come "cinematico".

Questa corrispondenza può essere considerata un romanzo autobiografico dove l'Io è il personaggio principale e gioca un doppio ruolo: quello di colui che guarda e quello di colui che è guardato. L'Io nelle lettere cessa di essere solo colui che racconta, ma diventa anche colui che si percepisce e si auto analizza: «Les lettres deviennent un 'laboratoire épistolaire' dans lequel on élabore une forme nouvelle: le roman moderne» (p. 136).

Nella conclusione l'A. si domanda se l'aspetto romanzesco delle lettere sia coscientemente ricercato oppure no, se esse rivestano il ruolo di opera letteraria involontaria o di creazione cosciente. Poiché «le romanesque à l'époque était omniprésent dans le champ culturel, qu'il imprégnait les esprits et les œuvres» (p. 159) esso sembra essere la manifestazione di una competenza culturale, di un luogo comune, a cui la marchesa aderisce naturalmente.

Madame de Sévigné racconta episodi della sua vita, realtà quali amore, guerra, morte: tematiche letterarie per eccellenza, che sono presentate con tratti romanzeschi.

11 Infine l'A. si chiede se sia possibile definire opera letteraria un testo che non è stato scritto con l'intenzione di essere pubblicato, concludendo «qu'en écrivant à sa fille Mme de Sévigné faisait œuvre littéraire, probablement sans le savoir et sans le vouloir. [...] Le romanesque [...] est loin d'être le seul ou le principal charme des lettres. Mais il est comme la lumière dans laquelle baigne l'écriture. L'esprit de la marquise est imprégné du monde des romans dont l'ombre portée donne du relief à ce qu'elle raconte» (pp. 163-164). 